\title{
Bioinspired metal-polymer thin films with varying hydrophobic properties
}

\author{
J. Rao, S. S. Anjum, M. Craig, J. R. Nicholls
}

(C) The Author(s) 2017. This article is an open access publication

\begin{abstract}
Nanocomposites involve the inclusion of one material into the layers of another material at a nanoscale level. Inspired by nature, nanocomposites material systems offer functionalities over their bulk forms which in some cases have evolved over millions of years. Here, thin film coatings have been fabricated by PVD sputtering, comprising a soft PTFE phase which is combined with a hard metallic NiTi phase. A series of coatings with PTFE ranging from 10 to $75 \mathrm{vol} \%$ have been prepared, and their surface energies and microstructures investigated. The surface energy of the nanocomposite films changes with the PTFE content, falling in the range between PTFE and NiTi with water contact angles between $80^{\circ}$ and $102^{\circ}$ for a thin film with 25 and $75 \mathrm{vol} \%$ of PTFE, respectively. Here, both TEM and EDX reveal PTFE forming along NiTi column boundaries. Coatings with PTFE content greater than $50 \mathrm{vol} \%$ failed due to a build-up of intrinsic stress. The degree of hybridization between NiTi and PTFE was found to be dependent on the PTFE layer thickness. SEM analysis of this coating reveals PTFE at the surface embedded within the NiTi matrix.
\end{abstract}

Keywords Nanocomposites, PVD Sputtering, Thin Films, Biomimetics, Sensors, Wear

J. Rao ( $\varangle)$, S. S. Anjum, M. Craig,

J. R. Nicholls

School of Aerospace, Transport and Manufacturing, Surface

Engineering and Nanotechnology Institute (SENTi),

Cranfield University, Cranfield, Bedfordshire MK430AL,

UK

e-mail: j.rao@cranfield.ac.uk

\section{Introduction}

Bioinspired material designs with multifunctional characteristics aim to offer properties similar to their counterparts found in nature, which in some cases have evolved over millions of years. For example, natural tissue comprises layers of hard and soft tissue material called tropocollagen and hydroxyapatite are organized into staggered arrays to form collagen fibrils. ${ }^{1}$ The ratio between the soft and hard material phases varies according to the tissue's functionality, e.g., muscular or epithelial tissue. ${ }^{2}$ The layers form a compact but strong and flexible lamella with load bearing, lubricious, and wear resistant characteristics. The soft material phase has elastomer characteristics and provides a dampening effect, whereas the hard material phase provides strength and load bearing characteristics. Another example involves micturition, a urethral function that relaxes the urethra voluntarily when it senses the bladder is full. ${ }^{3}$ Here, the combination of the surface energy of the material, which determines the water contact angle (WCA), and the frictional properties of the tissue plays a significant role in defining the wetting and fluid flow characteristics down the urethral tissue. ${ }^{3-5}$ This principle could be applicable to cases where the ability to modify a surface between hydrophilic and hydrophobic can, for example, be used to increase engine component lifetimes. In a modern stop-start engine for example, increased wetting during the stop-phase could be used to prevent premature engine wear by always maintaining a thin oil film layer in areas where there is potential of metal-to-metal contact. Since the WCA of a material affects its wetting properties, the ability to modify this characteristic by the way of incorporating a secondary low-surface energy material is investigated. In fact, modifying the surface energy of a metal layer with the addition of a hydrophobic layer has been reported before, where tungsten is coated with PTFE to a form a hydrophobic 
surface. ${ }^{6}$ Incorporating a low-surface energy material such as PTFE with NiTi as the initial choice of materials in this study is driven by their biocompatibility and the need for intelligent in vivo drug delivery applications, where current challenges include the need to administer the correct dose and quantity of drugs when most needed by a patient. ${ }^{7}$ Thin films comprising a soft PTFE phase, which has hydrophobic characteristics, have been combined with a harder NiTi metal phase, a shape memory alloy (SMA) material that offers shape memory functionality in response to heat or stress. It is well documented that SMAs transform from a low temperature, low allotrope martensite B19' monoclinic phase, to a high temperature, high-symmetry allotrope austenite $\mathrm{B} 2$ cubic phase. NiTi undergoes such a B2-B19' phase transformation but is limited to a maximum operating temperature of around $100^{\circ} \mathrm{C} .^{8}$ Thus, the combination of the material biocompatibility and the shape memory functionality could, in theory, be applicable in drug delivery systems as part of a nano-fluid sensor which triggers a dose of drugs that is administered in response to a patient's body temperature. Thin films are prepared by sputter physical vapor deposition (PVD) as this allows for the control of individual film thicknesses at a nano-level, permitting a greater control of film microstructure. ${ }^{9}$ The objective is to modify the surface energy by varying the amount of PTFE and NiTi content in the coating and investigate the resultant wetting and microstructural properties. This study continues our initial research on such coatings where the tribological properties such as the coefficient of friction were measured and the concept of introducing a polymer-shape memory alloy nanocomposite film was initially proposed. ${ }^{10}$

\section{Method}

The coatings were prepared in a Leybold L560 sputtering machine equipped with two 3-inch-diameter magnetrons-NiTi, powered by a dual-output Advanced Energy Pinnacle ${ }^{\circledR}$ pulse dc supply operating at $200 \mathrm{kHz}$ at a $1.6 \mu$ s duty factor, and PTFE powered by an RF power supply operating at $13.56 \mathrm{MHz}$. Sputtering power densities ranged between 3.5 and $5.3 \mathrm{~W} / \mathrm{cm}^{2}$. Prior to deposition, the system was turbopumped to a base pressure around $1 \times 10^{-6} \mathrm{mbar}$, and then Ar gas flowed at a controlled rate to realize the experimental process pressures. The targets were sputter-cleaned (presputtering) for 5 min prior to each sputtering run to remove any impurities. The nanocomposite films were prepared by one of three system operating modes-stationary or rotational, details of which follow, or by the familiar co-sputtering route. In the stationary mode of deposition, the substrate is placed above a magnetron and the target material sputtered for a preset time to produce the coating. The substrate is then moved to the second magnetron and again sputtered for a predetermined time period, producing a thin film coating by the classical layer-by-layer approach. ${ }^{11}$ Modifying the hybrid nature of the nanocomposite was achieved by varying the volume fraction of PTFE within the thin film, realized by altering the time spent over each magnetron, which in turn altered the layer thickness of either NiTi or PTFE. This approach follows from previous work by this group on multilayer thin film coatings, ${ }^{12}$ where the wavelength $(\lambda)$ is defined as the sum of the two layers, namely $T_{\mathrm{P}}$ and $T_{\mathrm{M}}$, corresponding to the thickness of the polymer and the metal layers, respectively.

$\lambda=T_{\mathrm{P}}+T_{\mathrm{M}}$

The volume $(\%)$ of the polymer content in the coating $\left(V_{\mathrm{P}}\right)$ could then be varied according to:

$V_{\mathrm{P}}(\%)=\frac{T_{\mathrm{P}}}{\left(T_{\mathrm{P}}+T_{\mathrm{M}}\right)} \times 100$

Layered coatings with $V_{\mathrm{P}}$ ranging between $10 \%$ and $70 \%$ have been fabricated with a $\lambda=200 \mathrm{~nm}$. In the rotation mode of deposition, the substrate table is rotated continuously during deposition over both magnetrons at a controlled speed, producing an interrupted staggered arrangement of nano-layers with nano-level interplanar spacing. ${ }^{13}$ The layer thicknesses are defined by the time resident over each of the targets; high rotational speeds reduce the time spent above each target and hence lead to thinner layers, whereas low rotational speeds increase the resident time over each target thereby increasing the layer thickness. In the co-sputter route, the substrate is placed between the PTFE and NiTi targets, and deposition occurs by operating both targets simultaneously. The coatings were prepared to realize a total thickness of $2 \mu \mathrm{m}$. Film composition is controlled by modifying the target power densities. Glass and $\mathrm{Si}$ wafers were used as substrates to prepare the nanocomposite thin films, which were cleaned prior to deposition using IPA. Static water contact angle (WCA) measurements were taken by the sessile droplet method, using a syringe filled with deionized water with a volume of $1.0 \mu \mathrm{L}$ at dosing rate of $2.0 \mu \mathrm{L} /$ s. An adjustable cold light source was used to illuminate the sample. The instrument uses SCA20 software to capture images and calculate the WCA. An SEM system, FEI XL30 SFEG equipped with energydispersive X-ray spectroscopy (EDX) operated at $20 \mathrm{kV}$, was used to investigate the film surface and elemental composition, respectively. TEM images were taken by a JOEL 2000FX TEM equipped with an Oxford Instruments EDX detector, housed at Loughborough University. Samples for TEM were prepared by focused ion beam (FIB), FEI FIB200, which uses gallium ions at a beam current ranging between 1 and 11,500 pA. 


\section{Results and discussion}

\section{PTFE thin films}

The energetics of the sputtering process can affect the polymerization of the complex functional groups in PTFE. ${ }^{14,15}$ An important factor to establish first is whether sputtering retains the polymerization of the deposited material. ${ }^{16,17}$ To ascertain the polymerized content, Fourier transform infrared spectroscopy (FTIR) was conducted on a number of PTFE films deposited by RF sputtering under various processing conditions. The main features of an FTIR spectrum from PTFE are the strong absorption bands between 1000 and $1400 \mathrm{~cm}^{-1}$, characteristic of $\mathrm{C}-\mathrm{F}_{X}(X=1,2)$ stretching vibrations. An analysis of the resultant FTIR spectrum obtained in this study is shown in Fig. 1. The area under the $\mathrm{CF}_{X}(X=1,2)$ peaks is associated with highly polymerized PTFE. ${ }^{18}$ The area under the peak at $900 \mathrm{~cm}^{-1}$ is associated with $\mathrm{CF}_{3}$ and is related to the polymer chain ends, where more monomeric, fragmented, or highly branched PTFE would have more $\mathrm{CF}_{3} .{ }^{19}$ Thus, the greater the area under this peak, the lower the polymerized content. An ideal PTFE film prepared by a sputtering route would therefore have a large area under the $\mathrm{CF}_{\mathrm{X}}$ peak compared to the area under the $\mathrm{CF}_{3}$ peak. Additionally, the presence of $\mathrm{CF}_{3}$ and $\mathrm{CF}_{2}$ radicals in sputtered PTFE thin films contribute to reducing the surface energies, thereby resulting in a hydrophobic surface. ${ }^{20}$ The optimum polymerization for RF-deposited films in this study was at a power of $150 \mathrm{~W}$ and a pressure of $15 \mathrm{mbar}$ (presented in Fig. 1), since these processing conditions minimized the degree of crosslinking and unreacted monomers which would produce less continuous films, supporting previous studies by Stelmashuk. ${ }^{21}$ These process conditions were adopted for subsequent fabrication of the intercalated PTFE-NiTi thin films. The findings support previous studies on sputtered PTFE films where it was determined that the degree of crosslinking is not affected as a result of sputter ion bombardment. ${ }^{14,19,22,23}$ Additionally, it has been noted that films with reduced polymerization had rougher surfaces owing to changes in their functional groups which produced excessive crosslinking and a high proportion of unreacted monomers. ${ }^{18,19,24,25}$

\section{NiTi thin films}

Pulse-DC sputter-deposited intermetallic NiTi thin films are amorphous and require subsequent post-heat treatment and annealing to realize reversible martensitic to austenitic (B2-B19') phase transformations. ${ }^{26}$ $\mathrm{NiTi}$ thin film coatings with the $\mathrm{Ti}$ content varying between 40 and 54 at\% have been prepared. The temperatures at which the martensite and austenite phases begin, peak, and end have been measured by differential scanning calorimetry (DSC). The data plotted in Fig. 2 show only the austenitic peak phase temperature, which increases proportionally with increasing $\mathrm{Ti}$ content in near equiatomic NiTi, supporting other studies, ${ }^{8,27}$ and demonstrating an upper transition temperature that can be varied in the range -20 to $140^{\circ} \mathrm{C}$.

The NiTi composition making up the nanocomposite films was selected as $47 \mathrm{at} \% \mathrm{Ti}$, since this composition realized a peak austenitic phase transformation close to body temperature. As the nanocomposite films cannot be heat treated due to the low melting temperature of PTFE, the phase transformations in NiTi are instead triggered by NiTi's pseudoelastic characteristics. $^{26}$

\section{Nanocomposite thin films}

The thin films prepared in this study are presented in Table 1 along with the measured WCA and their mode of fabrication. A thin film of RF-sputtered PTFE is hydrophobic having the highest measured WCA of $108^{\circ}$. On the other hand, a thin film of pulse-DC sputtered NiTi exhibits hydrophilic characteristics with a measured WCA of $55^{\circ}$.

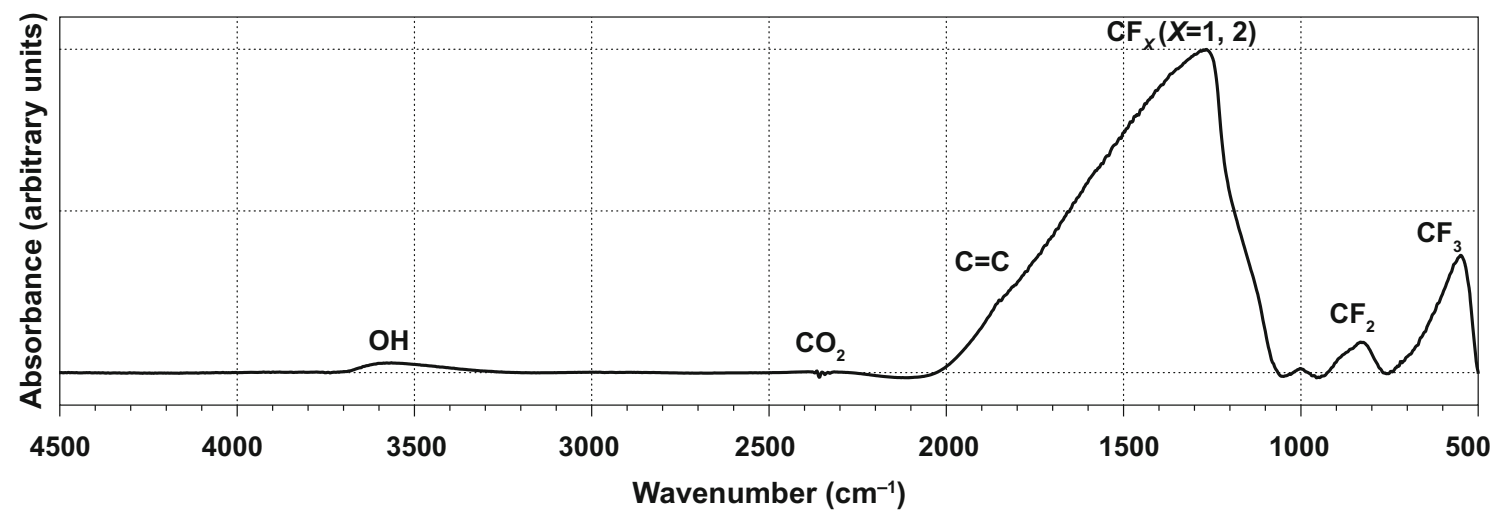

Fig. 1: FTIR spectra of a PTFE film fabricated on a glass substrate. The strong absorption bands between 1000 and $1400 \mathrm{~cm}^{-1}$ relate to $C-F_{X}(X=1,2)$ stretching vibrations: RF sputter-deposited film at $150 \mathrm{~W}$ and 15 mbar chamber pressure 


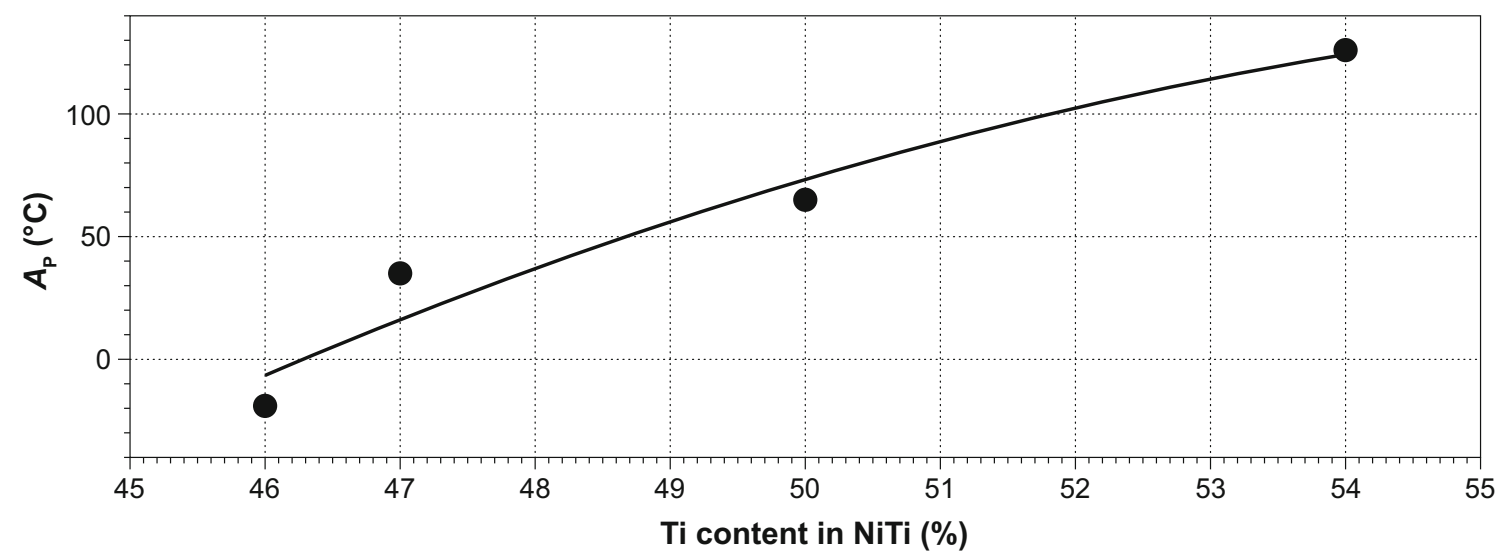

Fig. 2: A plot of the change in austenitic phase transformation temperature with increasing Ti in NiTi. This linear increase in phase transformation temperature with Ti content has been reported by other studies ${ }^{27}$

Table 1: PTFE-NiTi nanocomposite thin films investigated in this study

\begin{tabular}{llll} 
Sample ID & $V_{\mathrm{p}}(\%)$ & WCA $\left(^{\circ}\right)$ & Deposition mode \\
\hline PTFE & 100 & 108 & - \\
$\mathrm{NiTi}$ & - & 55 & - \\
$\mathrm{A}$ & 10 & 88 & Layered \\
$\mathrm{B}$ & 25 & 79 & Layered \\
$\mathrm{C}$ & 50 & 68 & Layered \\
$\mathrm{D}$ & 75 & 102 & Layered \\
$\mathrm{E}$ & 35 & $96 \rightarrow 52$ & Co-sputtered \\
$\mathrm{F}$ & 54 & $102 \rightarrow 43$ & Co-sputtered \\
$\mathrm{G}$ & 25 & 99 & Hybrid \\
$\mathrm{H}$ & 10 & 87 & Rotated \\
\hline
\end{tabular}

$V_{\mathrm{P}}$ represents the vol\% of PTFE in the coating. Films with a PTFE content greater than $30 \%$ subsequently failed due to an increase in stress build-up. The WCA of samples labeled here as E and F dropped during the measurements

a Film deposition by first layering and then co-sputtering

Figure 3 shows photographs of a droplet of water on the surface of the films and is used to determine the WCA. The deposition process was intentionally terminated on the NiTi layer in all films produced by the layered approach. The thin films have a measured WCA ranging between bulk PTFE and bulk NiTi, suggesting a varying degree of hybridization between the films and the deposition approached adopted. An increase in the PTFE content $\left(V_{\mathrm{P}} \%\right)$ in the coatings prepared via a layered route increases the measured WCA, approaching that of bulk PTFE in a thin film with 75 vol\% PTFE. The measured WCAs for both samples $\mathrm{C}$ and $\mathrm{D}$, having NiTi as their top layers, differ with $\mathrm{C}$ having a lower WCA than $\mathrm{D}$, suggesting that there is a greater degree of hybridization between PTFE and NiTi in sample D.

However, both samples subsequently failed due to intrinsic stresses, and no further analysis was possible. In fact, it was observed that films with PTFE greater than $30 \mathrm{vol} \%$ were all prone to mechanical instability as these films disintegrated soon after the WCA measurements were taken. Further analysis was there- fore not possible; however, an analysis of the material flakes suggests that the failure was cohesive, probably due to the intrinsic stressed state of the polymer phase interlayers producing delamination cracks along the polymer and metal interface, ${ }^{28}$ which constitutes a cohesive failure. As a route to overcome such in-built stresses, sample $G$ was fabricated by employing a hybrid approach-layered followed by co-sputtering. The thickness of the individual layers was intentionally reduced toward the surface as a route to reduce stress, and a series of 10 PTFE-NiTi layers with a volume fraction of $25 \%$ PTFE deposited. PTFE-NiTi was finally co-sputtered to complete film deposition. A TEM image of this film is shown in Fig. 4 and will be discussed later in this paper. Thin films that were deposited by co-sputtering proved unstable as their surface energy changed dramatically over the course of the WCA measurements, samples $\mathrm{E}$ and $\mathrm{F}$. The measured WCA dropped by $50 \%$ from around $100^{\circ}$ in the space of 10-15 s, suggesting that microstructural porosity and instability of the hybrid nanocomposite framework containing $30 \mathrm{vol} \%$ PTFE or greater were 


\section{Layer deposited}
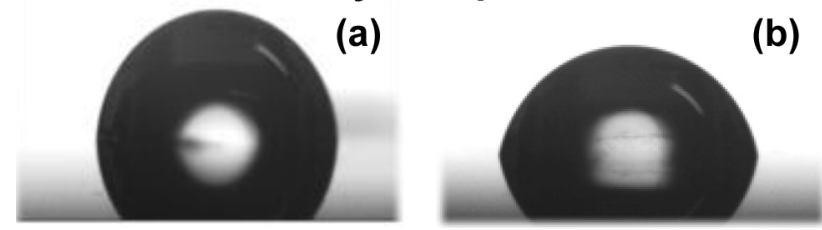

(c)

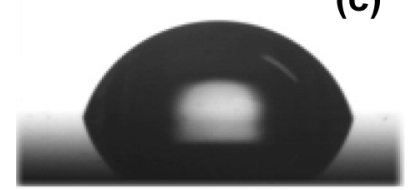

\section{Co-sputter deposited}

(e)

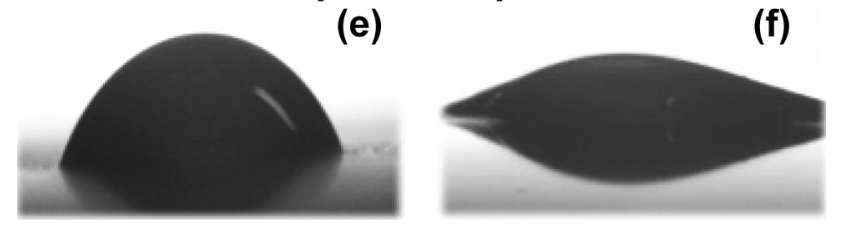

Hybrid

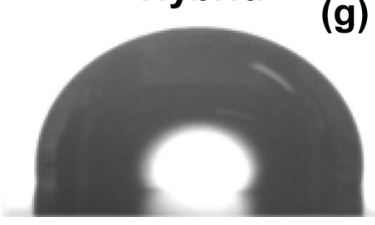

Fig. 3: Image of a water droplet on the surface of the nanocomposite films, which was used to measure the water contact angle (WCA). Apart from sample G, the samples were prepared using a layered approach with the process terminating on the NiTi layer. The WCAs are between bulk PTFE and NiTi

responsible. The quantity of water absorbed was measured by dropping a known volume of water on an area of the film. For a 2- $\mu$ m-thick film absorbing water over a $0.25 \mathrm{~cm}^{2}$ area, the amount of water absorbed was estimated to be approximately $0.017 \mu \mathrm{L}$. The absorbed volume of water represents the vacant volume within the thin film, which equated to around one-third of the total volume of the thin film. This is not attributed to simple evaporation due to the timescales (10-15 s) the measurements were taken over. The measured WCAs for the co-sputtered films suggest hydrophilic characteristics and support a previous study on nano-porous thin films, which concluded that water absorption was greater in films that were hydrophilic and porous. ${ }^{29}$

Figure 4 shows both the bright and dark-field TEM images of $G$, which on first viewing appear as distinct layers that decrease in thickness toward the surface. The co-sputtered top layer of the coating fell off, but the layered-deposited coating remained intact. PTFE appears as light-colored bands in (a) and appears as dark bands in (b). A close-up of the bright-field image in (c) shows, in addition to continuous PTFE layers running parallel to the substrate, deposition of further
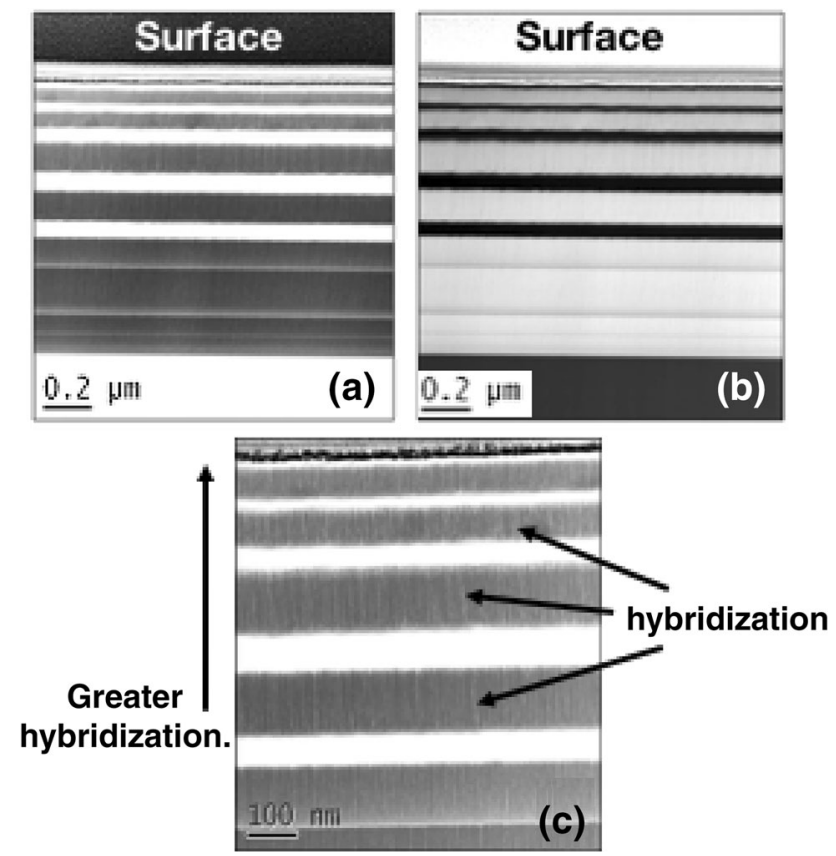

Fig. 4: TEM image of sample $H$ fabricated by a co-sputtering and a layered approach. (a) Bright-field image showing PTFE as the lighter bands, (b) dark-field image showing PTFE as the darker bands. (c) A close-up image of the sample showing greater hybridization as the PTFE layer thickness is reduced

PTFE along NiTi columnar boundaries. Also, as the layer thickness of PTFE is reduced, there is an increased visible evidence of PTFE forming along the NiTi column boundaries, i.e., there is an increasing degree of hybridization as the PTFE layers and NiTi layers become thinner toward the surface. The increasing level of hybridization is thought to be due to the repulsive interplay of the electronegative fluorine in PTFE and electrons in NiTi, in addition to intra-layer attraction between NiTi metallic cations and PTFE. To further test this hypothesis, a coating with a PTFE volume fraction of $10 \%$ (sample $\mathrm{H}$ ) was prepared.

The bright and dark-field TEM images taken of sample $\mathrm{H}$ are shown in Figs. 5a and 5b, respectively. The thicknesses of the PTFE layers are around $30 \mathrm{~nm}$, appearing as white bands running from left to right in $5 \mathrm{a}$ and as dark bands in $5 \mathrm{~b}$. In regions between the PTFE, within the NiTi layer (bands colored gray), there are visible signs that PTFE appears vertically running along NiTi column boundaries, thus supporting our notion of hybridization. However, it could be argued that such vertical bands could be empty and their gray coloration is in fact an atomic number contrast from a mixture of NiTi and PTFE. A study to investigate this further was undertaken using energydispersive X-ray analysis (EDX) SEM, and the results of which are shown in Figs. 5c and 5d, showing the $\mathrm{O}$ and $\mathrm{F} k-\alpha$ maps, respectively. 


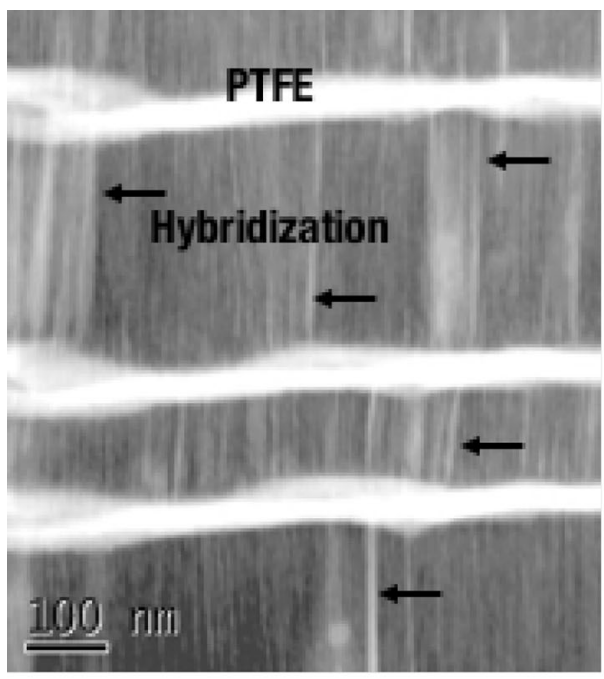

(a)

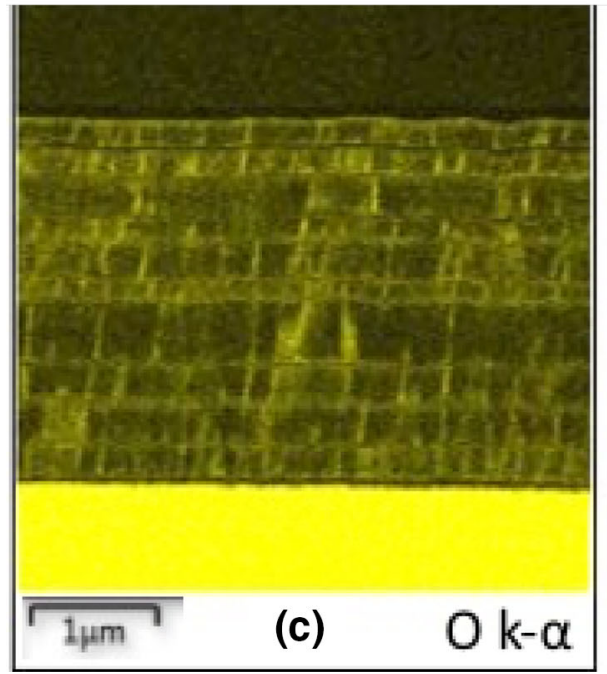

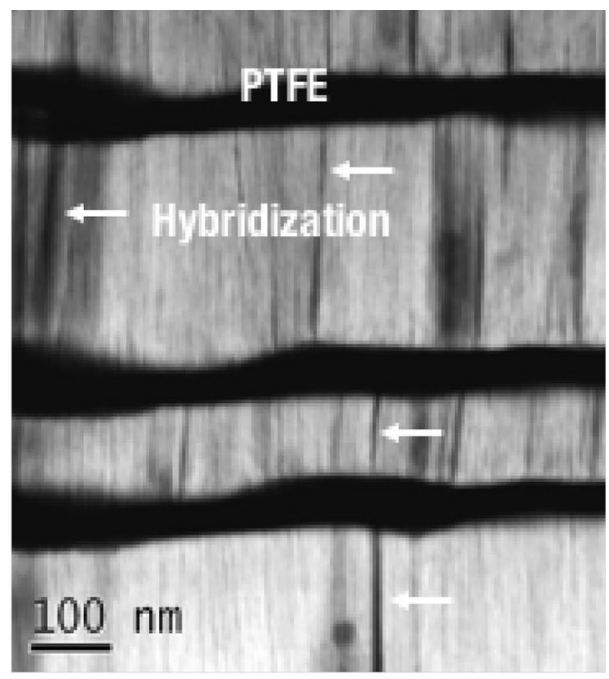

(b)

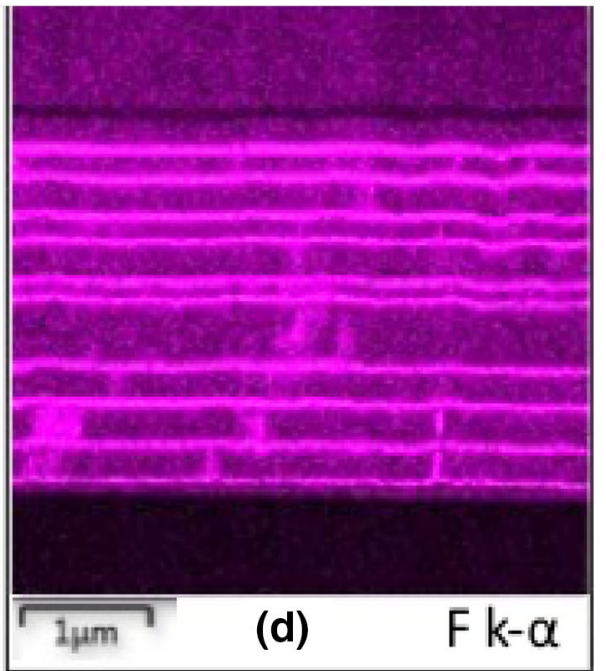

Fig. 5: An intercalated PTFE-NiTi thin film formed when the PTFE layers are reduced to $30 \mathrm{~nm}$, Sample H. (a) The brightfield image shows PTFE (light areas) forming along the column boundaries of the darker, NiTi layers. (b) A dark-field image of the same region of the structure. (c), (d) Energy-dispersive X-ray images of the $k \alpha{ }^{1} X$-rays from the $O$ and $F$, respectively, further supporting the notion of hybridization and where the fluorine in PTFE is observed running vertically between the NiTi column boundaries

By filtering only X-rays from $\mathrm{O}_{k \alpha}^{1}$ and $\mathrm{F}_{k \alpha}^{1}$, Figs. 5c and $5 \mathrm{~d}$, respectively, show that the fluorine from the PTFE appears as horizontal bright bands running parallel to the substrate, together with areas within the NiTi layer where fluorine is observed running vertically along NiTi column boundaries. The fluorine map implies the presence of PTFE and confirms the hybrid nature of the nanocomposite. We surmise that this occurs due to the intermolecular forces between the PTFE chains and crosslinked fragments which are arranged in both vertical and horizontal directions. ${ }^{30}$ Thus, both the TEM images and EDX analysis support our belief that the two materials produce a hybrid nanocomposite material. Evidence of this hybrid material with the PTFE polymer appearing on the surface of the coating is now presented. A study of the surfaces of the thin film samples $A$ and $H$ was undertaken using SEM, both produced with $10 \%$ volume fraction PTFE.

The surface of $\mathrm{H}$ comprises of PTFE hybridized within the NiTi matrix and thus accounts for the mixmode measured WCA (Fig. 6a). The surface of this film is compared and contrasted with $\mathrm{A}$, which also has the same measured WCA, but fabricated with thicker PTFE layers (Fig. 6b). The surface of A comprises dense columnar grains, characteristic of a PVD-sputtered film, with EDX analysis of these regions confirming NiTi-rich regions interspersed with PTFE-rich nodules on the film surface. From these images, we can conclude that $\mathrm{H}$ is more hybrid in nature than $\mathrm{A}$, which 


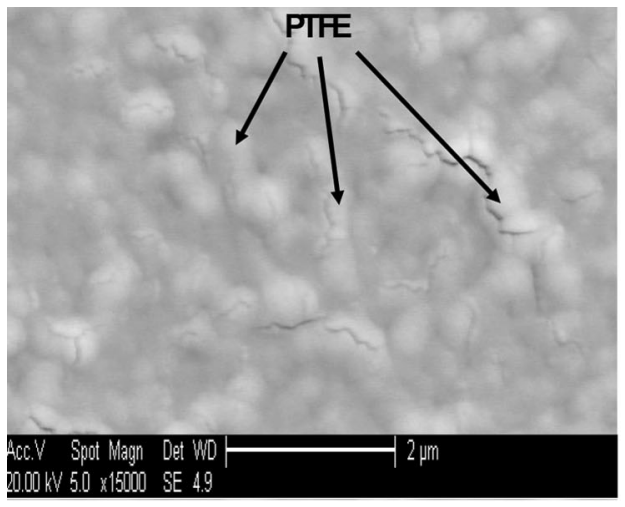

(a)

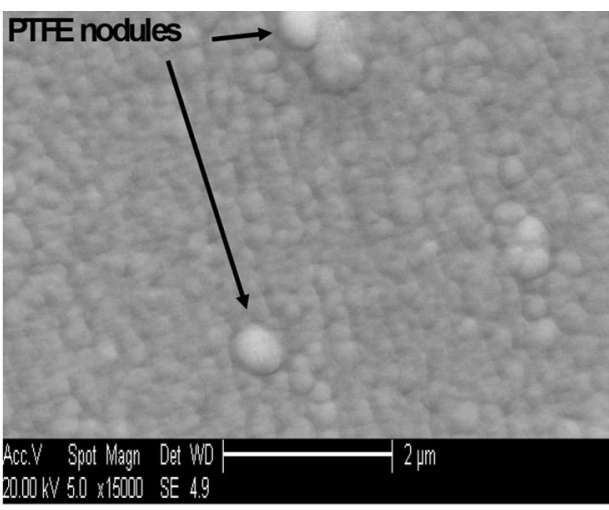

(b)

Fig. 6: Surface morphologies of two samples with the same $10 \%$ volume of PTFE, but prepared by (a) Sample H; rotation, (b) Sample A; layered

we understand to be due to the more stable and thinner PTFE and NiTi layers.

\section{Conclusions}

This work has demonstrated the successful fabrication of metal-polymer nanocomposite thin films by PVD sputtering. Nanocomposite thin films have been realized by either multilayering or continuously rotating above NiTi and PTFE targets during the deposition process. Co-sputtered films failed due to intrinsic stresses, and further analysis of this co-sputtered microstructure was not possible. Furthermore, films with PTFE greater than $30 \mathrm{vol} \%$ were also shown to be unstable. Results from water contact angle measurements reveal that the surface of the nanocomposite films has a WCA that falls between that of a thin film of PTFE and NiTi. Further microstructural analysis using TEM reveals that the hybrid nature increases in films with thin $(30 \mathrm{~nm})$ PTFE layers, where EDX Xrays from $\mathrm{O}_{k \alpha}^{1}$ and $\mathrm{F}_{k \alpha}^{1}$ shows PTFE forming along NiTi column boundaries. Surface studies of two films with the same vol\% of PTFE but with different PTFE layer thicknesses have different morphologies. The surface of the coating fabricated with $30 \mathrm{~nm}$ PTFE layers has visible PTFE at the surface and growing between the voids in the NiTi metal matrix, whereas a coating with thicker PTFE layers has a surface more like that of a PVD-deposited metallic coating (NiTi was the topmost layer).

It is proposed that the characteristics of such films could, in theory, suit a future drug delivery system which responds to a patient's body temperature to administer drugs accordingly. Another potential application is where a hydrophobic film needs to be maintained, for example, in bearings designed for cyclic stop-start applications. Changes in the austenite to martensite transformations in the $\mathrm{NiTi}$ alloy could be employed to modify the surface energies in response to the external environment.

Acknowledgments The authors greatly appreciate the TEM and EDX data of the films undertaken by Dr Geoff West, Loughborough University, Leicestershire, UK, LE11 3TU.

Open Access This article is distributed under the terms of the Creative Commons Attribution 4.0 International License (http://creativecommons.org/licenses/by/4.0/), which permits unrestricted use, distribution, and reproduction in any medium, provided you give appropriate credit to the original author(s) and the source, provide a link to the Creative Commons license, and indicate if changes were made.

\section{References}

1. Chen, PY, McKittrick, J, Meyers, MA, "Biological Materials: Functional Adaptations and Bioinspired Designs." Prog. Mater. Sci., 57 1492-1704 (2012). doi:10.1016/j.pmatsci.2012.03.001

2. Oelze, ML, Zachary, JF, O'Brien, WD, Jr, “Characterization of Tissue Microstructure Using Ultrasonic Backscatter: Theory and Technique for Optimization Using a Gaussian form Factor." J. Acoust. Soc. Am., 112 1202-1211 (2002). doi:10.1121/1.1501278

3. Fowler, CJ, Griffiths, D, de Groat, WC, "The Neural Control of Micturition." Nat. Rev. Neurosci., 9 453-466 (2008). doi:10.1038/nrn2401

4. Griffiths, DJ, "The Mechanics of the Urethra and of Micturition.” Br. J. Urol., 45 497-507 (1973)

5. Kuru, M, "Nervous Control of Micturition." Physiol. Rev., 45 425-494 (1965)

6. Bayat, A, Ebrahimi, M, Moshfegh, AZ, "Correlation Between Surface Roughness and Hydrophobicity of GLAD RF Sputtered PTFE/W/Glass Nanorod Thin Films." $V a$ cuum, (2014). doi:10.1016/j.vacuum.2013.09.007 
7. LaVan, DA, McGuire, T, Langer, R, "Small-Scale Systems for In Vivo Drug Delivery." Nat. Biotechnol., 21 1184-1191 (2003). doi:10.1038/nbt876

8. Wibowo, E, Kwok, CY, "Fabrication and Characterization of Sputtered NiTi Shape Memory Thin Films." J. Micromech. Microeng., 16 101-108 (2006). doi:10.1088/0960-1317/ 16/1/014

9. Petrov, I, Barna, PB, Hultman, L, Greene, JE, "Microstructural Evolution During Film Growth." J. Vac. Sci. Technol. A Vac. Surf. Films, 21 S117 (2003). doi:10.1116/1.1601610

10. Anjum, SS, Rao, J, Nicholls, JR, "Polymer (PTFE) and Shape Memory Alloy (NiTi) Intercalated Nano-biocomposites." IOP Conf. Ser. Mater. Sci. Eng., Vol. 40, p. 12006 (2012)

11. Lehnert, T, Grimmer, H, Böni, P, Horisberger, M, Gotthardt, R, "Characterization of Shape-Memory Alloy Thin Films Made Up from Sputter-Deposited Ni/Ti Multilayers." Acta Mater., 48 4065-4071 (2000). doi:10.1016/S13596454(00)00189-0

12. Rao, J, Cruz, R, Lawson, KJ, Nicholls, JR, "Sputtered DLC$\mathrm{TiB}_{2}$ Multilayer Films for Tribological Applications." Diam. Relat. Mater., (2005). doi:10.1016/j.diamond.2005.06.015

13. Rojas, TC, Domínguez-Meister, S, Brizuela, M, García-Luis, A, Fernández, A, Sánchez-López, JC, "A Nanoscale Characterization with Electron Microscopy of Multilayered CrAlYN Coatings: A Singular Functional Nanostructure." Microsc. Microanal., 20 14-24 (2014). doi:10.1017/ S1431927613013962

14. Lawson, KJ, Nicholls, JR, In: Hougham, G, Cassidy, PE, Johns, K, Davidson, T (eds.) Fluoropolymers 1: Synthesis, pp. 313-320. Springer, Boston (2002) doi:10.1007/0-306-469189_19

15. He, J, Li, W, Wang, L, Wang, J, Li, H, “Deposition of PTFE Thin Films by Ion Beam Sputtering and a Study of the Ion Bombardment Effect." Nucl. Instrum. Methods Phys. Res. Sect. B Beam Interact. Mater. Atoms, 135 512-516 (1998). doi:10.1016/S0168-583X(97)00630-7

16. Drábik, M, Polonskyi, O, Kylián, O, Čechvala, J, Artemenko, A, Gordeev, I, et al., "Super-hydrophobic Coatings Prepared by RF Magnetron Sputtering of PTFE." Plasma Process. Polym., 7 544-551 (2010). doi:10.1002/ppap.200900164

17. Oya, T, Kusano, E, "Characterization of Organic Polymer Thin Films Deposited by rf Magnetron Sputtering." Vacuum, 83 564-568 (2008). doi:10.1016/j.vacuum.2008.04.040

18. Biederman, H, Bílková, P, Ježek, J, Hlídek, P, Slavínská, D, "RF Magnetron Sputtering of Polymers." J. Non Cryst. Solids., 218 44-49 (1997). doi:10.1016/S0022-3093(97)00196-8

19. Bodas, DS, Mandale, AB, Gangal, SA, "Deposition of PTFE Thin Films by RF Plasma Sputtering on $\langle 100\rangle$ Silicon
Substrates." Appl. Surf. Sci., $245 \quad 202-207 \quad$ (2005). doi:10.1016/j.apsusc.2004.10.023

20. Tripathi, S, Haque, SM, Rao, KD, De, R, Shripathi, T, Deshpande, U, et al., "Investigation of Optical and Microstructural Properties of RF Magnetron Sputtered PTFE Films for Hydrophobic Applications." Appl. Surf. Sci., 385 289-298 (2016). doi:10.1016/j.apsusc.2016.05.121

21. Stelmashuk, V, Biederman, H, Slavansk, D, Zemek, J, Trchov, M, "Plasma Polymer Films rf Sputtered from PTFE Under Various Argon Pressures." Vacuum, 77 131-137 (2005). doi:10.1016/j.vacuum.2004.08.011

22. Roy, RA, Messier, R, Krishnaswamy, SV, "Preparation and Properties of r.f.-Sputtered Polymer-Metal Thin Films." Thin Solid Films, 109 27-35 (1983). doi:10.1016/00406090(83)90028-7

23. Faupel, F, Zaporojtchenko, V, Strunskus, T, Elbahri, M, "Metal-Polymer Nanocomposites for Functional Applications." Adv. Eng. Mater., 12 1177-1190 (2010). doi:10.1002/ adem.201000231

24. Li, L, Zi, FT, Zheng, YF, "The Characterization of Fluorocarbon Films on NiTi Alloy by Magnetron Sputtering." Appl. Surf. Sci., 255 432-434 (2008). doi:10.1016/j.apsusc.2008.06.174

25. Yamada, Y, Tanaka, K, Saito, K, "Friction and Damage of Coatings Formed by Sputtering Polytetrafluoroethylene and Polyimide." Surf. Coat. Technol., 43-44 618-628 (1990). doi:10.1016/0257-8972(90)90006-X

26. Zhang, X, Sehitoglu, H, "Crystallography of the B2 $\rightarrow$ R $\rightarrow$ B19' Phase Transformations in NiTi." Mater. Sci. Eng. A, 374 292-302 (2004). doi:10.1016/j.msea.2004.03.013

27. Sanjabi, S, Cao, YZ, Barber, ZH, "Multi-target Sputter Deposition of Ni50Ti50-xHfx Shape Memory Thin Films for High Temperature Microactuator Application." Sens. Actuators A Phys., 121 543-548 (2005). doi:10.1016/ j.sna.2005.04.006

28. Trostyanskaya, EB, Grabil'nikov, GV, Komarov, AS, "Interlayer Corrosion Cracking Resistance of Metal- and Polymer-Matrix Composite Materials." Mech. Compos. Mater., 22 639-644 (1987). doi:10.1007/BF00714815

29. Sultana, N, Khan, TH, "Water Absorption and Diffusion Characteristics of Nanohydroxyapatite (nHA) and Poly(hydroxybutyrate-co-hydroxyvalerate-) Based Composite Tissue Engineering Scaffolds and Nonporous Thin Films." $J$. Nanomater., 2013 1-8 (2013). doi:10.1155/2013/479109

30. Zhao, Q, "Effect of Surface Free Energy of Graded NI-PPTFE Coatings on Bacterial Adhesion." Surf. Coat. Technol., 185 199-204 (2004). doi:10.1016/j.surfcoat.2003.12.009 